\title{
Fortuitous detection of uniparental isodisomy of chromosome 6
}

Marcelo C Bittencourt, Michael A Morris, Jacqueline Chabod, Arnaud Gos, Bernard Lamy, Florence Fellmann, Stylianos E Antonarakis, Emmanuel Plouvier, Patrick Herve, Pierre Tiberghien

Etablissement de Transfusion Sanguine de Franche-Comté, Besançon, France M C Bittencourt

J Chabod

B Lamy

P Herve

$P$ Tiberghien

Division of Medical Genetics, Geneva

University Hospital,

Switzerland

M A Morris

A Gos

$S$ E Antonarakis

Laboratoire de F Fellmann

Service de Pédiatrie, CHU Besançon,

France

E Plouvier

Correspondence to:

Dr Tiberghien,

Immunomolecular

Etablissement de

Transfusion Sanguine de

Boulevard Fleming

BP 1937, Besançon Cedex,

France.

Received 20 May 1996

for publication

6 August 1996 Cytogénétique, CHU Besançon, France

Histocompatibility and

Therapeutics Laboratory,

Franche-Comté, 1

Revised version accepted

\begin{abstract}
Uniparental isodisomy is defined as the inheritance of two copies of the same parental chromosome and can result in defects when it produces homozygosity for a recessive mutation or in the presence of imprinting. We describe the detection of a chromosome 6 uniparental isodisomy in a 9 year old girl, discovered during a search for an HLA identical sib. HLA typing, erythrocyte phenotyping, and genotypes of microsatellite polymorphisms were compatible with a paternal isodisomy of chromosome 6, with normal biparental origin of the other chromosomes. Paternal cells were not responsive to the patient's cells in mixed lymphocyte cultures. This fortuitous detection of a chromosome 6 isodisomy suggests that cases of chromosome 6 UPD may not be deleterious and may therefore go undetected.

(F Med Genet 1997;34:77-78)
\end{abstract}

Keywords: isodisomy; chromosome 6; HLA typing.

In 1980 , Engel ${ }^{1}$ defined theoretically the concept of uniparental disomy (UPD) as the inheritance of both copies of a chromosome from only one parent. The majority of UPD cases result from meiotic non-disjunction events. ${ }^{2}$ Two subtypes of UPD can be established: heterodisomy occurs when the inheritance of gen-

\begin{tabular}{|c|c|c|c|}
\hline $\mathbf{a}$ & b & c & d \\
\hline $\mathrm{A} 3$ & A9 & A2 & A28 \\
\hline B7 & B14 & B5 & B49 \\
\hline DRB1*0405 & DRB1 ${ }^{*} 1001$ & DRB1 ${ }^{*} 0701$ & DRB1 ${ }^{*} 0406$ \\
\hline DQB1 ${ }^{*} 0302$ & DQB1 ${ }^{*} 0501$ & DQB1 ${ }^{*} 0201$ & DQB1 ${ }^{*} 0402$ \\
\hline DPB1*0401 & $\begin{array}{r}\text { DPB1 }{ }^{*} 01011 \\
{ }^{*} 01012\end{array}$ & DPB1*1701 & DPB1 ${ }^{*} 1701$ \\
\hline
\end{tabular}

Figure 1 HLA typing of the family. The patient is represented by a solid symbol. The haplotypes were deduced by segregation analysis and are indicated by arbitrary lower case letters. etic material is from both chromosomes of a parental pair; isodisomy is present when two copies of the same parental chromosome are inherited, a condition with increased risk for recessive disorders. However, heterodisomy and isodisomy are not mutually exclusive for a given chromosome, and therefore UPD may have both heterodisomic and isodisomic segments. Both forms of UPD can cause disorders by unmasking genomic imprinting. Several reported cases of UPD involving various chromosomes are associated with deleterious effects. ${ }^{23}$ We describe here a fortuitously discovered case of chromosome 6 paternal isodisomy.

The patient is a 9 year old girl, of Algerian origin, with $\beta$ thalassaemia major confirmed by haemoglobin electrophoresis. No phenotypic abnormalities were noted on physical examination other than mild growth retardation probably related to her red blood cell disorder. Her weight and height at birth were $2800 \mathrm{~g}$ (25th centile) and $50 \mathrm{~cm}$ (75th centile) and at present are $20 \mathrm{~kg}$ (10th centile) and $123 \mathrm{~cm}$ ( 25 th centile). She and her family were referred for HLA typing to identify potential donors for allogeneic bone marrow transplantation (BMT). HLA class I typing of all family members was performed using the standard microlymphocytotoxicity test. HLA class II typing was performed by hybridisation with sequence specific oligonucleotides after polymerase chain reaction DNA amplification for DRB1, DQB1, and DPB1 loci.

HLA typing of the family and segregation analysis showed that the patient was homozygous for the paternal haplotype with no inheritance of a maternal haplotype (fig 1). The other sibs had normal inheritance of both maternal and paternal HLA haplotypes. Karyotype analysis of the patient was normal. Phenotyping of erythrocyte markers (for which the genes are located on chromosomes $1,4,7$, 18,19 , and 22) was performed. Additional genotypes were obtained for the patient and her parents at five highly informative microsatellite polymorphisms from chromosome 6 ( $6 \mathrm{p}$ and $6 q)$ as well as from seven other autosomes (table 1). The results were entirely compatible with a paternal isodisomy of chromosome 6 with normal biparental origin of the other chro- 
Table 1 Microsatellite polymorphism genotyping of chromosome 6 and seven other autosomes

\begin{tabular}{|c|c|c|c|c|c|c|c|c|c|c|c|c|}
\hline & \multicolumn{5}{|c|}{ Chromosome 6} & \multirow{2}{*}{$\frac{c h r 1}{D 1 S 436}$} & \multirow{2}{*}{$\frac{c h r 5}{D 5 S 351}$} & \multirow{2}{*}{$\frac{c h r 7}{D 7 S 507}$} & \multirow{2}{*}{$\frac{\text { chr } 11}{D 11 S 1985}$} & \multirow{2}{*}{$\begin{array}{l}\operatorname{chr} 12 \\
\text { D12S79 }\end{array}$} & \multirow{2}{*}{$\begin{array}{l}\text { chr } 15 \\
G A B R A\end{array}$} & \multirow{2}{*}{$\frac{c h r 19}{A P O C 2}$} \\
\hline & $\begin{array}{l}S C A 1 \\
(6 p)\end{array}$ & $\begin{array}{l}\text { HLA superlocus } \\
(6 p)\end{array}$ & $\begin{array}{l}T N F x \\
(6 p)\end{array}$ & $\begin{array}{l}T N F \beta \\
(6 p)\end{array}$ & $\begin{array}{l}D 6 S 1009 \\
(6 q)\end{array}$ & & & & & & & \\
\hline $\begin{array}{l}\text { Father } \\
\text { Child } \\
\text { Mother }\end{array}$ & $\begin{array}{ll}1 & 2 \\
2 & 2 \\
3 & 3\end{array}$ & $\begin{array}{ll}1 & 2 \\
2 & 2 \\
3 & 4\end{array}$ & $\begin{array}{ll}1 & 3 \\
3 & 3 \\
1 & 2\end{array}$ & $\begin{array}{ll}2 & 3 \\
3 & 3 \\
1 & 2\end{array}$ & $\begin{array}{ll}1 & 2 \\
1 & 1 \\
3 & 3\end{array}$ & $\begin{array}{ll}1 & 4 \\
1 & 3 \\
2 & 3\end{array}$ & $\begin{array}{ll}3 & 4 \\
2 & 4 \\
1 & 2\end{array}$ & $\begin{array}{ll}2 & 3 \\
1 & 2 \\
1 & 1\end{array}$ & $\begin{array}{ll}1 & 2 \\
1 & 3 \\
3 & 4\end{array}$ & $\begin{array}{ll}1 & 2 \\
2 & 3 \\
2 & 3\end{array}$ & $\begin{array}{ll}1 & 3 \\
2 & 3 \\
2 & 2\end{array}$ & $\begin{array}{ll}1 & 2 \\
1 & 3 \\
3 & 4\end{array}$ \\
\hline
\end{tabular}

Table 2 Mixed lymphocyte culture results

\begin{tabular}{|c|c|c|c|c|}
\hline \multirow[t]{2}{*}{ Responder cells } & \multicolumn{4}{|c|}{$\begin{array}{l}\text { Stimulator cells* (cpm) } \\
\text { SRR\%† }\end{array}$} \\
\hline & Proband & Mother & Father & Control \\
\hline Proband & 2550 & $\begin{array}{l}19527 \\
56 \%\end{array}$ & $\begin{array}{c}15126 \\
46 \%\end{array}$ & 36969 \\
\hline Mother & $\begin{array}{l}19803 \\
87 \%\end{array}$ & 1112 & $\begin{array}{l}46283 \\
109 \%\end{array}$ & 53379 \\
\hline Father & $\begin{array}{l}1085 \\
0.8 \%\end{array}$ & $\begin{array}{l}37675 \\
99 \%\end{array}$ & 942 & 66379 \\
\hline $\begin{array}{l}\text { Control } \ddagger \\
100 \% \mathrm{RR}\end{array}$ & $\begin{array}{r}24754 \\
41\end{array}$ & $\begin{array}{r}49283 \\
88\end{array}$ & $\begin{array}{r}45124 \\
79\end{array}$ & $\begin{array}{l}57550 \\
-\end{array}$ \\
\hline
\end{tabular}

* Stimulator cells were irradiated with 3000 rads.

† Stabilised relative response (RR): [RR of responder to control/100\%RR (RR of control to HLA mismatched control stimulator)] $\times 100$.

$\ddagger$ Mean values. Three different unrelated HLA mismatched donors were used as controls.

mosomes (probability of maternity $>99.9 \%$, Bayes theorem). However, because only one 6q marker was used, we cannot formally exclude the possibility of combined heterodisomy and isodisomy in this case. The $\beta$ thalassaemia trait was found in both parents. Microsatellite analysis excluded the possibility of uniparental isodisomy also at chromosome 11 , which contains the $\beta$ globin locus. ${ }^{4}$ Measurement of serum C4 levels showed normal results for the patient.

As expected with a paternal isodisomy of chromosome 6, mixed leucocyte cultures showed that the patient's cells did not stimulate paternal responder cells and that the patient's cells were, however, capable of responding to the father's cells (table 2). The reduced responsiveness of the proband's cells to her mother's cells could be explained by the hypothetical influence of NIMAs (non-inherited maternal HLA antigens), as previously postulated. ${ }^{5}$

In summary, we present the occurrence of a paternal isodisomy of chromosome 6 in a 9 year old girl with no apparent abnormality other than those related to $\beta$ thalassaemia. Uniparental disomy is a rare but recognised cause of at least three genetic disorders in humans and has been documented in several other pathological conditions involving different chromosomes. ${ }^{23}$ Reported cases of paternal isodisomy of chromosome 6 were associated with deficiency of the fourth component of complement ${ }^{6}$ and neonatal diabetes mellitus. ${ }^{78}$
In this respect, it has been suggested that an imprinted gene on chromosome 6 is central to the development and maturation of early fetal and neonatal pancreatic $\beta$ cell function. ${ }^{8}$ In our patient, no evidence for transient neonatal diabetes was found at birth. However, we cannot formally exclude this possibility. Maternal isodisomy of chromosome 6 in a renal transplant patient with no other genetic abnormality was recently reported. ${ }^{9}$

Uniparental disomy may hypothetically result in a pathology when it produces homozygosity for a recessive mutation or for imprinted genes. ${ }^{23}$ The description of both maternal and paternal isodisomy of chromosome 6 , with no apparent phenotypic abnormalities, suggests that there is no imprinting of genes on maternally and paternally derived chromosomes 6 . The fortuitous detection of chromosome 6 UPD in a $\beta$ thalassaemia patient indicates that some cases of UPD may go undetected in the population. However, the fact that this is the first such fortuitous detection of paternal UPD for an intensively studied chromosome (because of HLA typing) confirms the rarity of this condition. The results of HLA typing and mixed lymphocyte cultures suggest that the risk of graft $v$ host reaction associated with the use of the father for BMT would be acceptable.

1 Engel E. A new genetic concept: uniparental disomy and its potential effect, isodisomy. Am $\mathcal{F}$ Med Genet 1980;6:137-43. 2 Ledbetter DH, Engel E. Uniparental disomy in humans: development of an imprinting map and its implications for prenatal diagnosis. Hum Mol Genet 1995;4(special issue): prenatal

3 Cassidy SB. Uniparental disomy and genomic imprinting as causes of human genetic disease. Environ Mol Mutagen causes of human genetic

4 Beldjord C, et al. Uniparental disomy: a novel mechanism for thalassemia major. Blood 1992;80:287-9.

5 Wolde ST, et al. Influence of non-inherited maternal HLA intigens on . Infuence of non-inherid arthritis. Lancet 1993;341:200-2.

6 Welch TR, et al. Uniparental isodisomy 6 associated with deficiency of the fourth component of complement. $\mathcal{F}$ Clin Invest 1990;86:675-8.

7 Abramowicz MJ, et al. Isodisomy of chromosome 6 in newborn with methylmalonic acidemia and agenesis of pancreatic beta cells causing diabetes mellitus. $\mathcal{f}$ Clin Invest 1994;94:418-21.

8 Temple IK, et al. An imprited gene(s) for diabetes? Nat Genet 1995;9:110-12.

9 Vandenbergloonen EM, et al. Uniparental maternal disomy 6 in a renal transplant patient. Hum Immunol 1996;45: $46-51$. 